the method proposed for active soil acids could not be used in case all the acids and resulting salts formed a true solution.

Potter states that the method measures nothing more nor less than the amount of acids soluble in potassium acetate. There is absolutely no basis for this statement. In the case of the common acid upland mineral soils, it is usually impossible to wash out with water any considerable amount of the acids causing soil acidity, and usually the more these soils are washed with water the more acid do they become. If these soils are treated with a salt solution, the soil acids remove from the salt solution a certain amount of the base and thus liberate from the salt an equivalent amount of free acid in solution; or the soil acids may exchange wholly, or in part, iron and aluminum for the base of the salt, which again gives rise to an acid solution due to the ease of hydrolysis of iron and aluminum salts. The potassium acetate solution does not in any way dissolve any appreciable amounts of the active soil acids.

While it is perfectly evident that the avidity of an acid in colloidal solution is different than when in true solution, yet this does not affect the purposes of the method proposed. In the method proposed only such soil acids (active soil acids) as are free to react quickly with a base are considered. A method to be of any value in studying the effects of soil acidity on the fertility of these soils must measure the avidity of the soil acids in the condition that they actually exist in the soil. This is done as nearly as possible in the method proposed.

As the writer has pointed out in Wisconsin Research Bull. $4 \mathrm{I}$, p. 34 , it is undoubtedly these active soil acids which limit the supply of calcium carbonate and bicarbonate in the soil solution to such an extent that the crop-producing capacity of some acid soils is affected. If this is the case it is evident that the avidity of the acids causing soil acidity may be of more importance than the total amount of acids present. The writer has found that soils may have a high total active acidity, but, because the avidity is low, the soils do not respond much to liming. Again soils having only a moderate active acidity but of high avidity respond decidedly to liming. The writer also has a considerable amount of data which indicate that the injurious effects of soil acidity are usually not due to a direct action of the soil acidity on the plants or biological processes, but that it is due to the too low rate at which the carbonic acid in competition with the soil acids is able to force out of the calcium compounds the calcium bicarbonate which is needed by plants and biological processes for maintaining the proper internal reaction.

Both from the theory involved and data secured from actual experiments, the writer is forced to disagree with the criticisms of Potter in every respect.

UNIVERSITY OF WISCONSIN

Madison, October 3, 1917

\section{THE WESTERN CHEMICAL MANUFACTURING COMPANY'S INDUSTRIAL COURSE}

Editor of the Journal of Industrial and Engineering Chemistry:

The article in the July issue of your magazine entitled "Another Possible Form of Coöperation between Universities and the Chemical Industries," page 638 , has come to our attention.

For a number of years it has been our custorn to employ students from local colleges for odd jobs in and about our plant for the summer months. We also have adopted what we call an Industrial Course, in which we enter recent college graduates for any sort of work encountered in a plant such as ours is. The wages at the start are those of an ordinary workman. The men are asked to do any sort of work there is to do and are not confined to any one department but are shifted from place to place and thus are made familiar with all the details of our various processes: these include the manufacture of sulfuric, nitric and muriatic acids (both commercial and chemically pure), com- mercial and C. P. aqua ammonia, anhydrous ammonia, and the dressing of complex zinc-lead-iron sulfide ores.

From the men entered in this course we select those best qualified for taking charge of departments, laboratory men, etc. All of our present heads of departments have been through this course-in fact we would not consider employing outside professional men, except perhaps in the case of the installation of a process, the details of which are more or less unfamiliar to us.

In other words, we have found it more practical to train our men along lines to which we have given much careful thought and attention.

The 1917 vacation period is over, but there may be some who would consider entering our industrial course and we would be pleased to hear from such persons.

During the past summer we employed quite a few college men from the local colleges, more than the usual number for the summer months, and we were glad to do it, for we believe the benefit was mutual. You will understand, of course, that we can give such work to only a limited number.

Owing to the fact that our plant is so far from the Eastern colleges, we do not believe it will be practical for the men from such colleges to come so far west, considering the little time they will have, the railroad fare to and from Denver, and the fact that there are several colleges in and around Denver. Conditions, of course, would be different in the case of those men who would be permanent.

Denver, Colorado September 22, 1917 Western Chemical MFg. Co. per PaUl, C. SkINNER, Treasurer and General Superintendent

\section{KILN DRYING OF WOOD}

Editor of the Journal of Industrial and Engineering Chemistry:

I have just read your splendid editorial on "Aviation and the Chemist" in the September number of ThIs Journal. I am sure you will be interested in the progress being made along the lines you mention and was about to call our work on kiln drying to your attention when I received a letter from Dr. Hawley in which he states he has already mentioned this to you briefly.

This I aboratory has been giving a great deal of time to the study of kiln drying of wood, both from a theoretical and practical side. Conditions necessary to proper drying of wood have been explained theoretically and methods of drying developed accordingly. Several kilns are now in operation at this laboratory where these methods can be tried out experimentally, and it bas been possible to dry various species and various forms with entirely satisfactory results. After tests in the experimental kilns it has been our policy to make demonstrations in commercial kilns to assist the industries in solving their drying problems.

In the present emergency the laboratory has been found well equipped with data already available to meet the problems in kiln drying woods, or to make further tests where necessary. It has been possible to kiln dry spruce green from the saw and in as good, if not better, condition than air-dried stock for airplane construction. Tests on ash are nearly completed and indications are that results will be satisfactory.

We are gradually developing specifications for drying all commercial species that will insure good results with any kiln in which the specified conditions can be maintained.
Forest Products LABoRATORY
Madison, Wrs., September 20,1917
C. P. WINSLow, Director

\section{AVAILABLE OXYGEN IN PYROLUSITE-CORRECTION}

In the article by O. L. Barnebey, Thrs Journal, 9 (I9I7), 961 , the missing footnotes on page 962 , second column, fourth paragraph, are as follows:

1 DeBries. Verslag Akad. Wetenschappen, [3], 1 (1884), 114

2 Lemoine, Compt. rend., 112 (1891), 936, 992, 1124

- Lemoine and Poitevin, Ann. chim. phys., [3], 62 (1861), 192. 